\title{
HOT FORMING LIMIT CURVES FOR NUMERICAL PRESS HARDENING SIMULATION OF AISI 420C
}

\author{
'Bernd-Arno BEHRENS, 'Johanna UHE, ${ }^{1}$ Hendrik WESTER, ${ }^{1 *}$ Eugen STOCKBURGER \\ ${ }^{1}$ Institute of Forming Technology and Machines, Leibniz Universität Hannover, 30823 Garbsen, Deutschland, \\ stockburger@ifum.uni-hannover.de
}

https://doi.org/10.37904/metal.2020.3667

\begin{abstract}
A possible alternative to the established press hardening steel 22MnB5 are hot formed martensitic chromium steels. Both strength and ductility of the martensitic chromium steels can reach very high values with appropriate heat treatments. Therefore, car body parts with high crash safety can be produced by hot forming martensitic chromium steels. To identify the formability of a sheet metal, forming limit curves are state of the art. Conventional forming limit curves are recorded at room temperature and do not adequately describe the forming capacity for hot sheet metal forming as it strongly depends on temperature. Therefore, in this paper, an experimental-numerical method for determining quasi-isothermal FLC at high forming temperatures is applied to the martensitic chromium steel AISI 420C (X46Cr13) for forming temperatures between 750$1,050^{\circ} \mathrm{C}$ according to its process route. The results show an increase of the formability with rising forming temperature with the highest at $1,050^{\circ} \mathrm{C}$.
\end{abstract}

Keywords: Experimental-numerical material characterisation, Hot FLC, Hot sheet metal forming, Martensitic chromium steel

\section{INTRODUCTION}

The use of hot formed components has gained significantly in importance, especially in the automotive industry. This is due to the increasing demands on car body components in terms of weight reduction in order to reduce $\mathrm{CO}_{2}$ emissions or extend the range of electric cars, maintaining the same stiffness and also increasing crash safety. In this context, hot forming processes such as press hardening, were established for the production of structural parts [1]. In this process, usually manganese-boron steels are used, which are first austenitised in a furnace. In the next step, the blanks are transferred to a tool, in which the forming and hardening process is carried out. Press hardening can be used to produce high mechanical properties. Strengths of more than 1,500 MPa and elongations at fracture up to $7 \%$ can be achieved using $22 \mathrm{MnB} 5$ [2]. Examples of press-hardened structural parts of the car body are the A- and B-pillar, roof frame, and tunnel. A possible alternative to $22 \mathrm{MnB} 5$ is the use of martensitic chromium steels such as AISI $420 \mathrm{C}$ (X46Cr13) in hot sheet metal forming. Hot forming with subsequent heat treatment of AISI $420 \mathrm{C}$ opens up the possibility to achieve high strengths with significantly higher elongation at fracture in contrast to press hardening of $22 \mathrm{MnB}$. Maximum tensile strengths of up to $1,850 \mathrm{MPa}$ and simultaneously elongations at fracture of more than $12 \%$ can be achieved [3]. A further advantage is the lower critical cooling rate to produce a martensitic microstructure [4]. Nowadays, FE simulations are often used as a numerical calculation method for designing press hardening processes. By simulating the press hardening process, the number of time-consuming and expensive practical tests in the design phase can be minimised. Within the FE simulation of press hardening, interactions between the thermal, mechanical and material-related parameters have to be taken into account [5]. In order to take fully advantage of the maximum formability of a process, it is of great interest to determine the moment of material failure during the numerical design of the press hardening process. The use of forming limit curves (FLC) is the state of the art for determining the forming limit of sheet metal materials [6]. 


\section{FORMING LIMIT CHARACTERISATION AT HIGH TEMPERATURES}

\subsection{State of the art}

FLC are currently used for simulation-based predictions of material failure due to necking or crack occurrence [7]. A FLC describes strain states in the sheet plane that can be tolerated by the material without failure while forming. The geometry of the specimens, the equipment, the execution and the evaluation of the tests to determine the FLC are specified in the international standard ISO 12004-2 for room temperature [8]. Nakajima experiments are one way of recording FLC. The test set-up for Nakajima experiments consists of a hemispherical punch with a diameter of $100 \mathrm{~mm}$, a drawing ring and a blank holder. The aim of the test is to set and record the deformation under defined strain combinations using specimen geometries of different widths. Since the flow properties and the forming limit of a material both strongly depend on the forming temperature, conventional FLC do not adequately describe the forming limit of a sheet material during hot forming [9]. To perform temperature controlled FLC above $500{ }^{\circ} \mathrm{C}$, various approaches can be found in literature, where modified Nakajima set-ups are used [10-12]. Based on the recorded data, it can be concluded that the forming limit rises with increasing temperature [13]. There are various challenges occurring in the performing of hot FLC experiments compared to the standardised testing at room temperature, which are solved in different ways in the literature leading to different result qualities.

According to ISO 12004-2, a lubricant system consisting of a sandwich arrangement of PTFE foil, grease, soft PVC and again grease is recommended in order to reduce friction between punch and specimen and thus induce failure as close as possible to the pole tip [8]. This type of tribological system is not suitable, as the recommended lubricants are not designed for such high temperatures. Shi et al. used a mixture of graphite and molybdenum disulphide on the punch as a lubricant, but this led to a far off-centre failure [14]. Pellegrini et al. described two possibilities of lubrication [15]. In the first test series, a thin graphite foil was applied as lubricant between the punch and the specimen. In the second test series a punch with PVD coating based on AICrN and additionally boron nitride was used. The digital image calculations indicated improved friction properties and a more centred failure of the specimen compared to Shi et al. [14]. Li et al. and Min et al. used a piece of asbestos paper between the punch and the specimen in order to reduce the heat transfer and minimise the cooling of the specimen $[13,16]$. Unfortunately, this led to bad friction conditions resulting in a crack appearance far from the centre of the specimen.

A further problem is to ensure isothermal test conditions at elevated temperatures. The tool of Shi et al. could be heated up to a forming temperature of $800^{\circ} \mathrm{C}$ in order to ensure an isothermal environment during the test [14]. The test carried out by Li et al. and Min et al. were performed with a cold tool, a forming speed of $30 \mathrm{~mm} / \mathrm{s}$ and asbestos paper as isolation between punch and specimen $[13,16]$. The resulting problem was that the specimen was still in contact with the unheated blank holder as well as the die, thus losing heat. Furthermore, the increased forming speed compared to the standard of 1.0-2.0 mm/s from ISO 12004-2 [8] ensured a lower heat loss, but the failure behaviour of a material depends on the forming speed. The tools of the test rigs from Pellegrini et al. were heated to forming temperatures of up to $700{ }^{\circ} \mathrm{C}$ with heating cartridges in order to carry out the test isothermally [15]. In the described investigations, the maximum forming temperature while testing was $800^{\circ} \mathrm{C}$.

In the standard for recording FLC at room temperature ISO 12004-2 it is recommended to record the forming during the test with an optical measuring system in order to determine the time of failure precisely and to calculate the strains occurring on the basis of the stochastic pattern (online measurement) [8]. Circular patterns were applied by laser by Shi et al. and by chemical etching by Li et al. and Min et al. [13,14,16]. The evaluation was then performed offline using the deterministic circle pattern. Pellegrini et al. sprayed a stochastic pattern of boron nitride on the specimen and performed the measurement online with the optical measuring system Aramis [15]. With increasing forming temperature, the online measurement becomes more problematic. The stochastic pattern must be heat resistant and usually more scale is produced at higher temperatures. The 
temperature stability for spray paints is often exceeded after $500^{\circ} \mathrm{C}$. In addition, heat flicker increases with rising forming temperature, making online measurements more difficult.

Therefore, for FLC determination above forming temperatures of $800{ }^{\circ} \mathrm{C}$ a new method is required considering isothermal testing conditions, an appropriate good tribological system and online measurement while testing.

\subsection{New method for determination of isothermal hot FLC}

To perform an isothermal FLC test, an experimental test set-up has been developed. The optical measuring system Aramis from GOM GmbH and the test apparatus with thermal container as well as gas pressure springs are installed in a servo-hydraulic forming simulator from the company Instron (Figure 1).

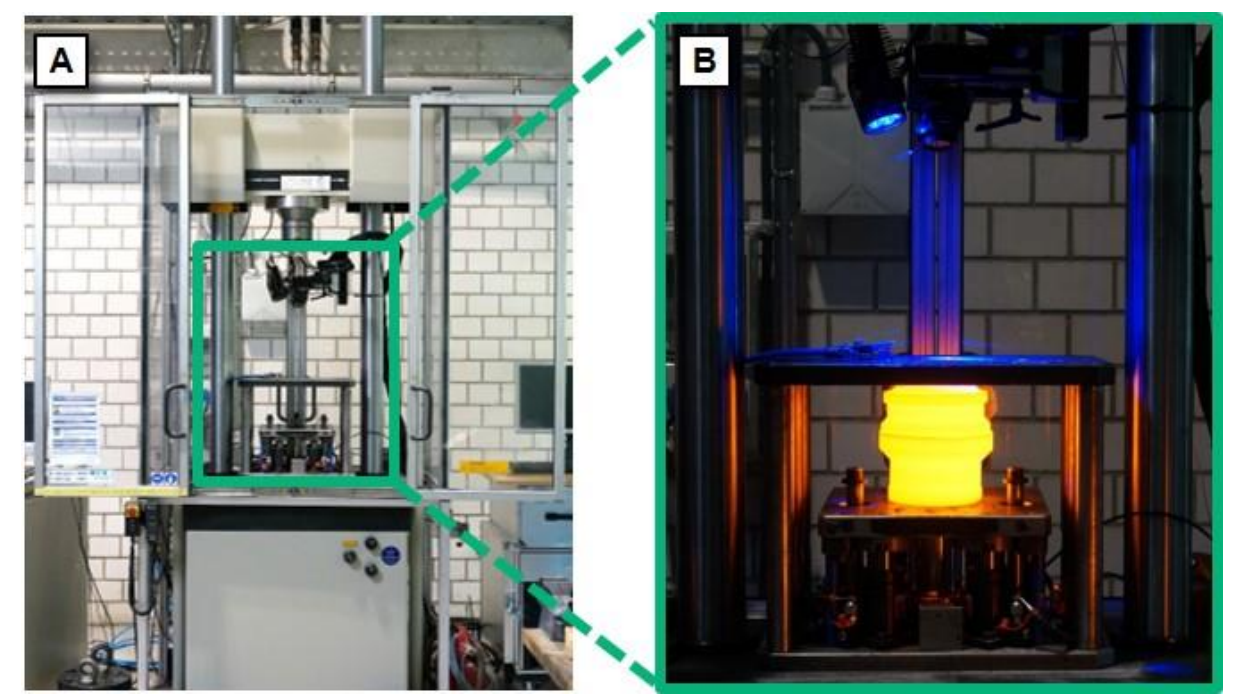

Figure $1(A)$ Isothermal hot FLC test set-up and (B) close-up of the thermal container

The thermal container, shown schematically in Figure $\mathbf{2} \mathbf{A}$, consists of a punch, an upper as well as a lower vessel and serves to maintain the forming temperature. When carrying out the tests for AISI $420 \mathrm{C}$, the specimen is heated first to $1,150{ }^{\circ} \mathrm{C}$ for $5 \mathrm{~min}$ in a furnace. The austenitisation temperature and time are defined based on the industrial process route to set the optimal mechanical properties of the material [17]. In parallel, the container is heated to a temperature above the forming temperature in another furnace. For example, a forming temperature of $750{ }^{\circ} \mathrm{C}$ requires a container temperature of $800{ }^{\circ} \mathrm{C}$. After heating, the specimen is transferred to the thermal container in the other furnace and subsequently both are installed in the test device. The measured forming temperature after transferring the thermal container is in the considered example approx. $750{ }^{\circ} \mathrm{C}$. Other forming temperatures are determined experimentally in the same way. The thermal container and thus the specimen are clamped by the gas pressure springs with a holding force $F_{S}$ of $60 \mathrm{kN}$. The forming simulator moves the punch in the thermal container with a punch speed $v_{P}$ of $3 \mathrm{~mm} / \mathrm{s}$. During the experiments, the specimen deformation is measured by the optical measuring system GOM Aramis using a stochastic pattern of aluminium oxide powder on the specimen surface. Graphite foil is applied as a lubricant to reduce friction. Used specimen geometries are scaled standard Hasek specimens shown in Figure 2 B [18].

Due to the high austenitisation temperature of $1,150{ }^{\circ} \mathrm{C}$, the heat resistance of a conventional stochastic pattern by spray paint was exceeded. Therefore, an aluminium oxide powder has to be used to apply the pattern. In order to withstand the heat treatment, the stochastic pattern could only be applied roughly and hence only large facets can be used for the calculation of the FLC by digital image correlation. However, the strain calculation depends on the facet size, so that large facets underestimate the occurring strains. The displacement in z-direction, on the other hand, is relatively independent of the facet size. Therefore, the 
calculation of the major and minor strains was done using a numerical model. A digital twin is created with the FE software Simufact Forming 16. The geometry of the model is based on the dimensions of the thermal container and the associated boundary conditions are derived from the experiments. The experimental zdisplacement at failure $S p$ for each specimen geometry measured by the optical measurement system is used in the simulation for defining the moment of material failure. The simulation model and the experimentalnumerical FLC determination are shown more detailed by Stockburger et al. in [19]. Major and minor strains are analysed in each specimen geometry to create the hot FLC. With this test set-up and determination method, it is possible to record quasi-isothermal hot FLC at very high temperatures above $1,000{ }^{\circ} \mathrm{C}$. By this means, the forming limit of AISI $420 \mathrm{C}$ for a forming temperature of $750-1,050{ }^{\circ} \mathrm{C}$ has been characterised.
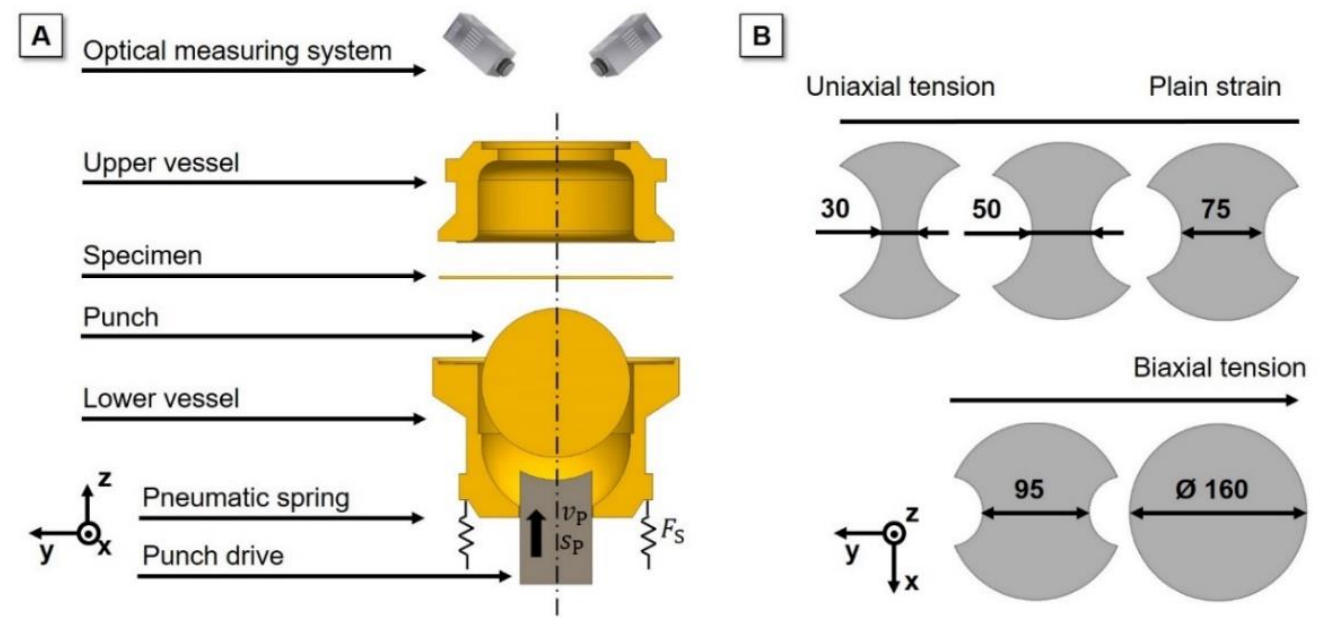

Figure 2 (A) Schematic illustration of the thermal container and (B) used hot FLC specimen geometry with widths in $\mathrm{mm}$

\section{RESULTS AND DISCUSSION}

Figure $3 \mathrm{~A}$ shows specimens of different widths after testing with graphite foil as lubricant at a forming temperature of $900{ }^{\circ} \mathrm{C}$. In addition, a tested specimen without lubricant is depicted. The crack occurs centred for all specimens with lubrication and particularly centred for the specimen with a width of $160 \mathrm{~mm}$ in comparison to the specimen without lubricant due to a better tribological system. The temperature in the middle of the specimen surface during forming was measured with an infrared sensor. Temperature over time curves are pictured exemplary for the specimen with a width of $50 \mathrm{~mm}$ for two retries in Figure $3 \mathbf{B}$. After the specimen gets into contact with the punch (approx. $1 \mathrm{~s}$ ), the temperature rises slightly and remains almost constant until the end of testing.

The determined major and minor strains using the experimental-numerical method are illustrated in Figure 4 A for the five examined specimen geometries of AISI $420 \mathrm{C}$ in $1.5 \mathrm{~mm}$. Furthermore, hot FLC for forming temperatures of $750{ }^{\circ} \mathrm{C}, 900^{\circ} \mathrm{C}$ and $1,050^{\circ} \mathrm{C}$ are calculated based on this data. The curves are also presented in Figure $4 \mathrm{~A}$. It can be identified that the forming limit is the highest at $1,050^{\circ} \mathrm{C}$ and is reduced with lower forming temperature. Interestingly enough, the major strain at $1,050^{\circ} \mathrm{C}$ and $900{ }^{\circ} \mathrm{C}$ is almost constant for the specimens with widths of $95 \mathrm{~mm}$ and $160 \mathrm{~mm}$. Usually, for FLC at room temperature a rise from the area of plain strain to biaxial tension can be observed [20]. It is assumed that the major strain is underestimated for the specimens with widths of $95 \mathrm{~mm}$ and $160 \mathrm{~mm}$, because the friction system is not as good as at room temperature, which has a higher influence for these specimens. The hot FLC can be plotted as a 3D surface function (Figure $4 \mathbf{B}$ ), which illustrates the influence of the forming temperature well and can be used in a numerical simulation as failure criterion. Compared to literature, improved lubrication and thus more centred failure of the specimen is achieved. However, the friction system is still not as good as at room temperature by ISO 12004 [8]. Although online strain calculation is not possible as suggested in [8], the moment at which 
the specimen fail is determinable using online measurement leading to a higher precision than offline measurement. Nevertheless, by using a heated thermal container, it is possible for the first time to record FLC isothermally for temperatures over $1,000^{\circ} \mathrm{C}$.

A Tests with lubrication

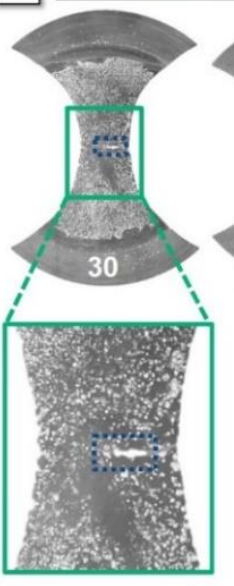

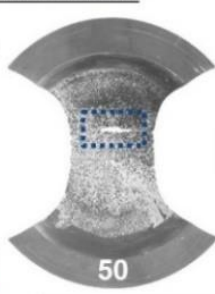

Test without lubrication

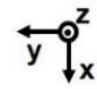

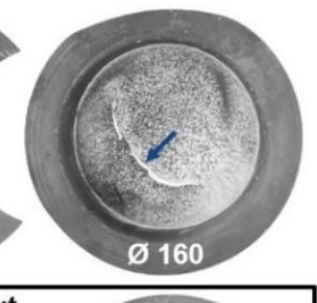

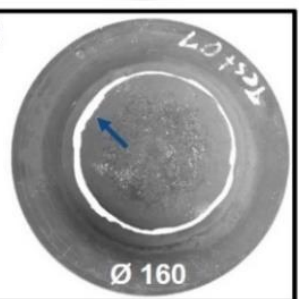

B

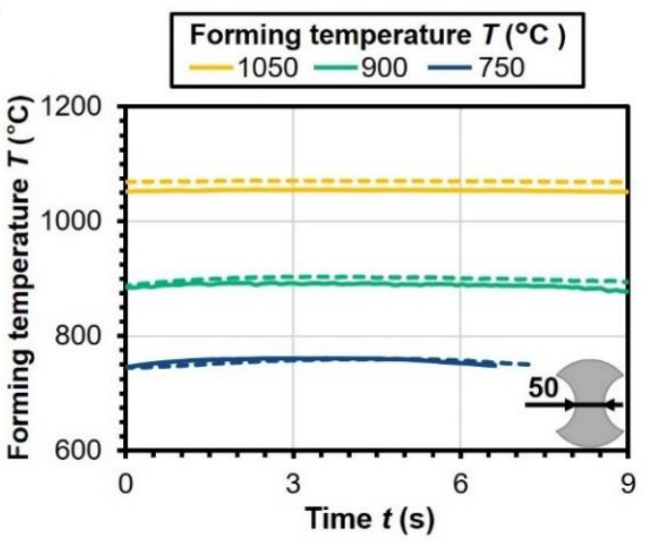

Figure $3(\mathrm{~A})$ Hot FLC specimen after testing with as well as without lubrication and (B) measured temperatures at the specimen surface for the hot FLC specimen with width of $50 \mathrm{~mm}$ while forming
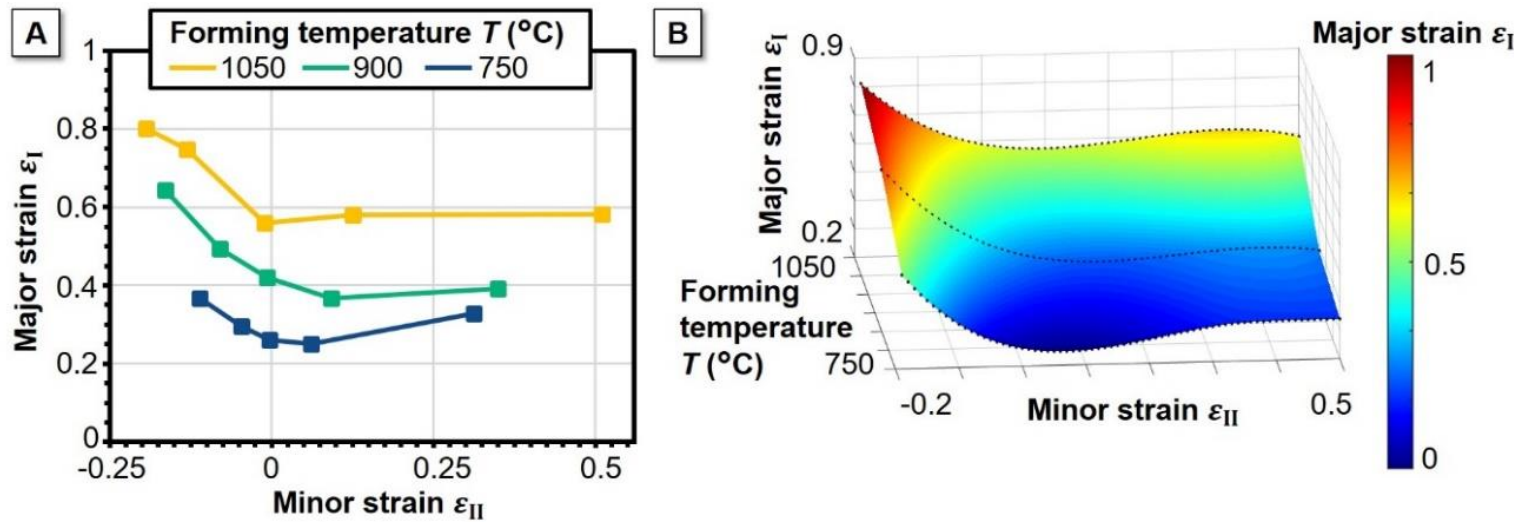

Figure 4 (A) Experimental-numerical hot FLC of AISI $420 \mathrm{C}$ in $1.5 \mathrm{~mm}$ for forming temperatures of $750{ }^{\circ} \mathrm{C}$, $900{ }^{\circ} \mathrm{C}$ as well as $1050^{\circ} \mathrm{C}$ and (B) 3D mapping of the hot FLC as surface function

\section{CONCLUSION AND OUTLOOK}

This study presents an experimental-numerical method for determining FLC at high temperatures. Quasiisothermal FLC tests for AISI $420 \mathrm{C}$ in $1.5 \mathrm{~mm}$ thickness were performed between $750-1,050{ }^{\circ} \mathrm{C}$. The strains at failure were calculated numerically and hot FLC were generated based on the results of the digital twins. In the following work, the material data will be implemented in a simulation model the design of hot forming processes and the hot FLC will be validated by experimental hot sheet metal forming tests.

\section{ACKNOWLEDGEMENTS}

The authors gratefully acknowledge the support of the German Research Foundation (DFG) within the project 385989694. Further Outokumpu Nirosta $\mathrm{GmbH}$ is thanked for providing the martensitic chromium steel AISI $420 \mathrm{C}$ for the investigations. 


\section{REFERENCES}

[1] BEHRENS, B.-A., JÜTTNER, S., BRUNOTTE, K., ÖZKAYA, F., WOHNER, M., STOCKBURGER, E. Extension of the Conventional Press Hardening Process by Local Material Influence to Improve Joining Ability. Procedia Manufacturing, 47, 2020, pp. 1345-1352.

[2] BEHRENS, B.-A., BOUGUECHA, A., GAEBEL, C. M., MORITZ, SCHRÖDTER, J. Hot stamping of load adjusted structural parts. Proc. of 11th International Conference on Technology of Plasticity ICTP, Nagoya, Japan, 2014, pp. 1756-1761.

[3] DAHMEN, M., JANZEN, V., LINDNER, S., WAGENER, R. Laser Beam Welding of Ultra-high Strength Chromium Steel. Physics Procedia, 56, 2014, pp. 525-534.

[4] MITHIEUX, J.-D., BADINIER, G., SANTACREU, P.-O., HERBELIN, J.-M., KOSTOJ, V. Optimized Martensitic Stainless Steels for Hot Formed Parts in Automotive Crash Application. Proc. of $4^{\text {th }}$ International Conference Hot Sheet Metal Forming of High-Performance Steel CHS', Lulea, Sweden, 2013, pp. 57-64.

[5] AKERSTRÖM, P., BERGMAN, G., OLDENBURG, M. Numerical implementation of a model for simulation of hot stamping. Modelling and Simulation in Materials Science and Engineering, 15, 2007, pp. 105-119.

[6] BANABIC, D. Sheet metal forming processes - Constitutive modelling and numerical simulation. Springer-Verlag, Berlin Heidelberg, Germany, 2010.

[7] BRUSCHI, S., ALTAN, T., BANABIC, D., BARIANI, P. F., BROSIUS, A., CAO, J., GHIOTTI, A., KHRAISHEH, M., MERKLEIN, M., TEKKAYA, A. E. Testing and modelling of material behaviour and formability in sheet metal forming. CIRP Annals - Manufacturing Technology, 63, 2014, pp. 727-749.

[8] BEUTH GMBH. ISO 12004-2:2019-06, Metallic materials, Sheet and strip, Determination of forming limit curves Part 2, Determination of forming-limit curves in the laboratory. Beuth Verlag, Berlin, Germany, 2019.

[9] CUI, J., SUN, G., XU, J., HUANG, X., LI, G. A method to evaluate the formability of high-strength steel in hot stamping. Materials \& Design, 77, 2015, pp. 95-109.

[10] TURETTA, A., BRUSCHI, S., GHIOTTI, A. Investigation of 22MnB5 formability in hot stamping operations. Journal of Materials Processing Technology, 177, 2006, pp. 396-400.

[11] BARIANI, P. F., BRUSCHI, S., GHIOTTI, A., TURETTA, A. Testing formability in the hot stamping of HSS. Manufacturing Technology, 57, 2008, pp. 265-268.

[12] CHASTEL, Y., DAHAN, Y., MASSONI, E., DUROUX, P., WILSIUS, J., HEIN, P. Formability of Quenchable Steels

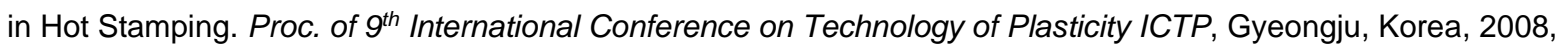
pp. 678-683.

[13] LI, F. F., FU, M. W., LIN, J. P., WANG, X. N. Experimental and theoretical study on the hot forming limit of 22MnB5 steel. The International Journal of Advanced Manufacturing Technology, 71, 2014, pp. 297-306.

[14] SHI, D. Y., YING, L., HU, P., LU, J. D., ZHAO, X., LIU, W. Q. Experimental and Numerical Determination of Thermal Forming Limit Diagrams (TFLD) of High Strength Steel 22MnB5. AIP Conference Proceedings, 1532, 2013, pp. 406-413.

[15] PELLEGRINI, D., LECHLER, J., GHIOTTI, A., BRUSCHI, S., MERKLEIN, M. Comparison of Forming Limit Curves for Hot Stamping of High Strength Steels. Key Engineering Materials, 410-411, 2009, pp. 297-304.

[16] MIN, J., LIN, J., LI, J., BAO, W. Investigation on hot forming limits of high strength steel 22MnB5. Computational Materials Science, 49, 2010, pp. 326-332.

[17] BEHRENS, B.-A., HÜBNER, S., SUNDERKÖTTER, C., GEBEL, L., GNAß, S., BERNDT, G., TRIMBORN, C., PFEFFER, C. Influence of process parameters on the hot stamping of carbon-martensitic chromium steel. Materials Science and Engineering, 418 (1), 2018, pp. 1-8.

[18] HASEK, V. Anwendung von Grenzformänderungsschaubildern. Industrie-Anzeiger, 99 (20), 1997, pp. 343-347.

[19] STOCKBURGER, E., WESTER, H., UHE, J., BRUNOTTE, K., BEHRENS, B.-A. Investigation of the forming limit behavior of martensitic chromium steels for hot sheet metal forming. Production at the leading edge of technology, Springer-Verlag, Berlin Heidelberg, Germany, 2019, pp. 159-168.

[20] BEHRENS, B.-A., BOUGUECHA, A., ROSENBUSCH, D., GRBIC, N., VUCETIC, M. Influence of the determination of FLC's and FLSC's and their application for deep drawing process. Proc. of $5^{\text {th }}$ International Conference on Advanced Manufacturing Engineering and Technologies, Belgrade, Serbia, 2017, pp. 405-415. 